\title{
High Fructose Corn Syrup and Sucrose Sweetened Milk Improve Dietary Quality during Weight Loss by Displacing Energy Dense, Nutrient Poor Foods
}

\author{
Stephanie Sinnett, Joshua Lowndes, Von Nguyen, Nan Lv, James Rippe* \\ Rippe Lifestyle Institute, 215 Celebration Place, Suite 300, Celebration, USA \\ Email: ssinnett@rippelifestyle.com, lowndes@rippelifestyle.com, vnguyen@rippelifestyle.com, \\ Ivanan@yahoo.com, ${ }^{*}$ jippe@rippelifestyle.com
}

Received 18 March 2014; revised 18 April 2014; accepted 26 April 2014

Copyright (C) 2014 by authors and Scientific Research Publishing Inc. This work is licensed under the Creative Commons Attribution International License (CC BY). http://creativecommons.org/licenses/by/4.0/

\section{(c) (i) Open Access}

\begin{abstract}
We examined dietary quality and weight loss among adults who drank flavored milk sweetened with either high fructose corn syrup (HFCS) or sucrose at average population consumption levels of fructose. This was a blinded, prospective randomized controlled trial evaluating the effects of $\mathbf{1 0 \%}$ or $\mathbf{2 0 \%}$ of calories from either HFCS or sucrose sweetened $1 \%$ fat, flavored milk as part of a hypocaloric diet. Participants $(n=98)$ followed this diet and completed three day food records at the beginning and end of the intervention. Results were pooled and compared with 31 non-milk drinking controls. Equivalent and significant weight loss occurred in all intervention groups whose data were pooled. Weight loss was different between the groups (weight loss and sweetened milk: pre: $192 \pm 28$ versus post: $183 \pm 28$ pounds; control: pre: $190 \pm 22$ versus post: $187 \pm$ 22 pounds, interaction $p<0.001$ ). Compliance to milk consumption was over $96 \%$. The increase in percentage of calories from carbohydrates (49 \pm 8 versus $55 \pm 6, p<0.001)$ and protein (17 \pm 5 versus $21 \pm 3, p<0.001$ ) was offset by a reduction in percentage of calories from fat (33 \pm 7 versus $24 \pm 5, p<0.001)$. Intakes of dietary calcium (839 \pm 377 versus $1530 \pm 407$ milligrams, p<0.001), vitamin $D(4 \pm 3$ versus $13 \pm 3$ micrograms, $p<0.001)$, potassium $(2417 \pm 766$ versus $3183 \pm 667$ milligrams, $p<0.001)$ and magnesium (272 \pm 83 versus $306 \pm 73$ milligrams, $p=0.001)$ increased, while sodium (3216 \pm 1161 versus $2253 \pm 684$ milligrams, $p<0.001)$ declined. We conclude that HFCS and sucrose consumed at $10 \%$ - $20 \%$ of calories may improve dietary quality during weight loss by improving compliance with nutrient dense foods such as low fat flavored milk.
\end{abstract}

\footnotetext{
"Corresponding author.
}

How to cite this paper: Sinnett, S., Lowndes, J., Nguyen, V., Lv, N. and Rippe, J. (2014) High Fructose Corn Syrup and Sucrose Sweetened Milk Improve Dietary Quality during Weight Loss by Displacing Energy Dense, Nutrient Poor Foods. Food and Nutrition Sciences, 5, 1005-1014. http://dx.doi.org/10.4236/fns.2014.511111 


\section{Keywords}

\section{HFCS, Sucrose, Dietary Quality, Milk}

\section{Introduction}

Milk is an important source of many macronutrients in the human diet. It is a key source of calcium, vitamin D, potassium, vitamin A, riboflavin, vitamin B12, zinc and magnesium [1]-[4]. Numerous studies have shown that milk drinkers are also more likely to meet dietary recommendations for many other nutrients [5] [6]. The Dietary Guidelines for Americans 2010 (DGA 2010) recommends increased milk consumption as part of an overall approach to consuming more nutrient dense foods [7]. Specifically the DGA 2010 recommends that children 2 8 years old consume two cups of fat free or low fat milk, or the equivalent of dairy servings and that people aged 9 or older consume 3 servings per day.

The DGA 2010 also identifies four "shortfall" nutrients of particular concern-calcium, potassium, vitamin D and fiber. Milk is the leading source of three out of these four shortfall nutrients. Moreover, the Institute of Medicine (IOM) has recommended substantial increases in the consumption of vitamin D and calcium [8]. It would be very difficult to reach these new recommendations without adequate consumption of milk in the diet [9]. For example, the US Department of Agriculture estimates that $70 \%$ of adolescent boys and $90 \%$ of adolescent girls do not meet the current calcium recommendations of $1300 \mathrm{mg} /$ day [10].

Despite abundant evidence of health benefits for consuming milk, both adults and children are falling far short of these recommendations. Only about 1/3 to 1/2 of American children and adolescent boys consume the recommended number of servings of milk or equivalent dairy products and less than one out of five adolescent girls meets this recommendation [11]. The average fluid milk consumption among adults is less than one cup per day [12].

The DGA 2010 document also recommends decreased consumption of added sugars as part of an overall strategy to improve dietary quality and lower the risk of weight gain and obesity [7]. Obesity and weight gain are significant problems, both for adults and children, in the United States. Currently $68 \%$ of the adult population in the United States is either overweight or obese and the prevalence of obesity, in particular, has continued to rise dramatically in the United States [13]. The prevalence of obesity amongst children has tripled in the last 30 years [14].

The Dietary Guidelines for Americans and the Surgeon General's Report on Obesity [15] both cite overconsumption of calories as the major nutritional problem facing the American public. Furthermore, at any given time, over half the adult population in the United States is on a weight loss program or otherwise trying to control their weight. Multiple studies have shown decreased caloric consumption is an effective strategy for losing weight [16]-[18], although some debate persists about whether or not there are particular macronutrient strategies for weight loss that are more effective than others. For example, a recent study showed that a Mediterranean approach to a weight loss diet, as well as a low carbohydrate approach, may out perform a low fat approach [19]. Other studies, however, have suggested that either low fat or low carbohydrate approaches to weight loss are essentially equivalent and that the key issue is finding a weight loss approach that is practical and will promote increased adherence [20].

Irrespective of macronutrient approaches taken to weight loss, concerns have been expressed about decreased dietary quality during weight loss when calories are restricted from a variety of sources. Since milk is a nutrient dense source of many important, and often under consumed nutrients, any weight loss strategy that further restricts low fat milk or other low fat dairy products would create particular concerns about diminished dietary quality.

The DGA 2010 document also raised concerns about added sugars in the diet, particularly in the area of weight management. Indeed, concern over added sugars in flavored milk has caused some schools to remove chocolate milk from school lunch menus [21], although some evidence suggests that this strategy results in significant decreases in all types of milk [22].

Flavored milk provides another option for meeting recommended intakes of dairy products. Some studies have suggested that amongst children more milk is consumed when flavored milk is offered as an option [23]. 
Very little is known about the effects of flavored milk consumption amongst adults. Finally, there are still lingering concerns about whether or not there are metabolic differences between high fructose corn syrup (HFCS) and sucrose [24], the two leading added sugars in the American diet and the two sugars which are commonly used to sweeten flavored milk.

The current study was undertaken to assess the impact of consuming low fat flavored milk at levels of dairy consumption recommended by the DGA 2010 as part of a hypocaloric diet on dietary quality and weight loss. A secondary goal of the current study was to assess if there were any differences between HFCS and sucrose at levels up to the $50^{\text {th }}$ percentile consumption level of fructose in the American diet.

\section{Materials and Methods}

\subsection{Study Design}

This study was a 24 week, randomized, prospective, double-blind trial involving 129 overweight/obese subjects in which we explored the impact of consuming either sucrose or high fructose corn syrup (HFCS) at the $25^{\text {th }}$ or $50^{\text {th }}$ percent population fructose consumption levels as a component of mixed nutrient, hypocaloric meal plans in a free living environment versus a control condition of no sweetened milk consumption. The sugars were provided in the form of sweetened, low fat milk so that the added sugars contributed either $10 \%$ or $20 \%$ of the daily allotted calories. Participants were randomly assigned to one of the four intervention groups (HFCS or sucrose at $10 \%$ or $20 \%$ of calories) or a non-interventional control group. The present study presents data on the four milk drinking groups combined $(\mathrm{n}=98)$ compared to the non-interventional controls $(\mathrm{n}=31)$.

\subsection{Subjects}

Men and women between the ages of 25 - 60 years of age with body mass index (BMI) $27.0-35.0 \mathrm{~kg} / \mathrm{m}^{2}$ were recruited. Exclusions included current enrollment in any commercial weight loss program, prescription medicines or supplements for weight loss, or a greater than five pound weight change during the past three months. Individuals with a history of orthopedic limitations that would interfere with the ability to meet prescribed exercise, a history of heart problems, a history of major surgery within the last three months, clinically diagnosed eating disorders or any gastrointestinal disorder, dietary restrictions or allergies to any component of the diet or which would limit the ability to adhere to dietary requirements of the study were all excluded. Physical activity was measured utilizing daily physical activity logs which were reviewed on a weekly basis by exercise physiologists or nutritionists. Cigarette smoking or the use of tobacco products, or consumption of greater than 14 alcoholic beverages per week were also excluded. Interested individuals were initially screened over the phone to determine eligibility based on self-reported data. A standardized screening form and phone script were developed to ensure individuals were screened in a consistent manner. Self-reported data including height and weight were verified during the initial clinical visit.

\subsection{Human Subjects Protection}

The study was approved by the Western Institutional Review Board (WIRB) (Project identification code: 20091302), date of approval: 07/28/09) and the University of Central Florida Institutional Review Board. (Project identification code: BIO-09-06189, date of approval: 07/08/09).

\subsection{Screening Visits}

Each subject performed a second screening visit one week later. During this visit, research dietitians assessed participant dietary intake by analyzing a completed three day food record using the Nutrient Data System Research (NDS-R) Software (University of Minnesota, Minneapolis, Minnesota, USA). Abdominal fat was assessed via Dual X-Ray Absorptiometry (General Electric iDXA) using the data from the "android" region defined as the region between the pelvis and $20 \%$ of the distance between the pelvis and the neck. All females were required to have a negative serum pregnancy test prior to DXA testing. Repeat measurements of body mass, body composition and dietary intake after the end of 24 weeks.

\subsection{Dietary Intervention}

Following completion of the two qualifying visits, individuals were randomly divided into either a hypocaloric 
diet with sugar sweetened milk or a non-interventional control group. Caloric intake for the hypocaloric groups was determined using the Mifflin-St. Jeor calculation [25] for resting energy expenditure (REE) with an individualized activity factor included (based on self-reported data on habitual physical activity) minus 500 kilocalories. Meal plans for all four hypocaloric groups were based on the American Diabetes Association (ADA) Exchange List and ranged from 50\% - 55\% carbohydrates, $15 \%$ - 20\% protein, and $25 \%$ - 30\% fat. Subjects in all four hypocaloric groups were carefully counseled by registered dietitians at diet initiation and weekly thereafter. Menu suggestions and recipes were provided to all volunteers. This was intended to reduce boredom with foods included in the diet and provide helpful guidance for subjects. Diet checklists were used by subjects so they could monitor appropriate consumption of all foods and beverages each day. Vigilant attention to portion size and condiments was emphasized. To promote adherence, foods within all meal plans were those foods that were affordable and fit into most people's lifestyle. At each weekly counseling session, dietitians reviewed dietary checklists with all the subjects to discuss challenges and encourage continued compliance. Participants in the intervention groups met with registered dietitians every week and dietary intake patterns were reviewed.

Individuals in the control condition followed their usual, habitual dietary patterns and met with exercise physiologists on a weekly basis to monitor their exercise prescription status. This was done to minimize the high attrition rates often associated with subjects in control groups that receive no intervention.

\subsection{Physical Activity}

The exercise prescription was the same in all participants and emphasized walking as the preferred form of exercise, however, other forms of exercise were not prohibited. Participants were asked to record information on daily physical activity. Duration of each exercise session was progressively increased from 15 minutes three days a week at the start of the study to 45 minutes three days a week at the end three weeks and remained at 45 minutes three days a week for the duration of the study. Subjects exercised between $60 \%$ and $80 \%$ of their maximal aerobic power using their predetermined maximal heart rate to regulate exercise intensity. An additional five minutes of warm up and ten minutes of cool down exercise were also included. To minimize overuse injuries, subjects were encouraged to use a variety of exercise modalities (e.g. walking, cycling, etc.). However, walking exercise was recommended as the main form of exercise.

\subsection{Statistical Analyses}

Data were checked for normalcy and analyzed using a two way (time and group assignment) Analysis of Variance (ANOVA) with repeated measures. Significant time $\mathrm{X}$ group assignment interactions were probed by using a one way ANOVA to compare the change in value (post test-baseline) between the hypocaloric and control groups. For all analyses the alpha value was set at 0.05 . All data were analyzed using IBM SPSS Advanced Statistics V18.

\section{Results}

In the entire intervention (milk consumption) cohort, all indices of body composition and fat decreased ( $\mathrm{p}<$ 0.001). These data are shown in Table 1.

The 98 participants who received weight-loss counseling while consuming sugar sweetened milk (distributed between 4 groups with varying amounts and type of sugar added to the milk) were pooled and compared to the 31 non-milk drinking, eucaloric exercising controls. Weight loss was different between the groups (weight loss and milk: $193.56 \pm 26.20$ versus $187.17 \pm 25.39$ pounds; Control: $189.60 \pm 22.07$ versus $187.28 \pm 21.81$ lbs, interaction $\mathrm{p}<0.001$ ).

Data on the change of fat measured in the android region (defined as the region between the pelvis and $20 \%$ of the distance between the pelvis and the neck) is shown on Table 2.

Despite a reduction in caloric intake in the weight loss and milk group (314.1 \pm 570.0 kilocalories) over four times greater than that in the control (73.9 \pm 635.1 kilocalories), the difference in response was not statistically significant (interaction $\mathrm{p}=0.055$ ). However, the dietary intervention did shift intake away from fat and towards carbohydrate and protein to a greater degree than in the control. These data are presented in Table 3.

The intervention also produced greater increases in intake of vitamin $\mathrm{D}$, calcium, magnesium and potassium and a greater decrease in sodium. These data are presented in Table 4. 
Table 1. Measures of adiposity and body composition in milk consuming group.

\begin{tabular}{ccc}
\hline Parameter Intervention Group (N = 98) & Baseline & Week 24 \\
\hline Body Mass (pounds) & $193.56 \pm 26.20$ & $187.17 \pm 25.39^{*}$ \\
Waist Circumference & $92.06 \pm 8.73$ & $88.61 \pm 8.61^{*}$ \\
Body Fat Percentage & $43.44 \pm 6.40$ & $41.46 \pm 7.65^{*}$ \\
Fat Mass (kilograms) & $36.85 \pm 7.66$ & $33.55 \pm 8.76^{*}$ \\
Fat Free Mass (kilograms) & $50.38 \pm 8.81$ & $49.79 \pm 8.78^{*}$ \\
Fat Percentage & $49.71 \pm 6.32$ & $46.67 \pm 9.17^{*}$ \\
Fat Mass of the Android Region (kilograms) & $3.40 \pm 0.92$ & $3.03 \pm 1.06^{*}$ \\
\hline
\end{tabular}
${ }^{*} \mathrm{p}<0.001$.

Table 2. Comparison of fat in android region intervention group versus controls.

\begin{tabular}{cccc}
\hline & & Baseline & Week 24 \\
\hline $\begin{array}{c}\text { Fat Percentage of the } \\
\text { Android Region }\end{array}$ & Milk and Weight Loss & $49.71 \pm 6.32$ & $46.67 \pm 9.17$ \\
& Control & $50.35 \pm 6.49$ & $49.56 \pm 6.86$ \\
$\begin{array}{c}\text { Fat Mass of the Android } \\
\text { Region (kilograms) }\end{array}$ & Milk and Weight Loss & $3.40 \pm 0.92$ & $3.03 \pm 1.06$ \\
\hline
\end{tabular}

*Android region is defined as the region between the pelvis and $20 \%$ of the distance between the pelvis and the neck as measured via DXA scan.

Table 3. Change in energy and macronutrient intake over the course of 24 weeks of hypocaloric (500 kilocalories/day) diet including sugar sweetened milk and in no-treatment controls.

\begin{tabular}{|c|c|c|c|c|}
\hline & & Baseline & Week 24 & Time X Group Interaction \\
\hline \multirow{2}{*}{ Energy Intake (kilocalories) } & Milk and Weight Loss $(\mathrm{n}=98)$ & $1991.9 \pm 638.7$ & $1677.9 \pm 362.7$ & \multirow{2}{*}{0.055} \\
\hline & Control $(\mathrm{n}=31)$ & $1926.7 \pm 500.4$ & $1852.9 \pm 745.9$ & \\
\hline \multirow{2}{*}{ Fat (\% of Calories) } & Milk and Weight Loss & $32.8 \pm 7.2$ & $24.1 \pm 4.6$ & \multirow{2}{*}{$<0.001$} \\
\hline & Control & $33.0 \pm 5.7$ & $30.4 \pm 8.9$ & \\
\hline \multirow{2}{*}{ Carbohydrate (\% of calories) } & Milk and Weight Loss & $49.1 \pm 7.8$ & $54.5 \pm 5.5$ & \multirow{2}{*}{$<0.05$} \\
\hline & Control & $50.2 \pm 7.0$ & $51.3 \pm 11.7$ & \\
\hline \multirow{2}{*}{ Protein (\% of calories) } & Milk and Weight Loss & $17.1 \pm 4.9$ & $21.1 \pm 3.0$ & \multirow{2}{*}{$<0.01$} \\
\hline & Control & $16.4 \pm 3.6$ & $17.3 \pm 5.0$ & \\
\hline
\end{tabular}

Table 4. Change in micronutrient intake over the course of 24 weeks of hypocaloric (500 kilocalories/day) diet including sugar sweetened milk and in no-treatment controls.

\begin{tabular}{|c|c|c|c|c|}
\hline & & Baseline & Week 24 & Time X Group Interaction \\
\hline \multirow{2}{*}{ Vitamin D (units) } & Milk and Weight Loss $(n=98)$ & $4.2 \pm 2.7$ & $12.5 \pm 3.1$ & \multirow{2}{*}{$<0.001$} \\
\hline & Control $(n=31)$ & $4.7 \pm 3.8$ & $4.9 \pm 3.7$ & \\
\hline \multirow{2}{*}{ Calcium (milligrams) } & Milk and Weight Loss & $838.8 \pm 376.7$ & $1529.6 \pm 406.7$ & \multirow{2}{*}{$<0.001$} \\
\hline & Control & $758.1 \pm 291.5$ & $813.2 \pm 506.3$ & \\
\hline \multirow{2}{*}{ Magnesium (milligrams) } & Milk and Weight Loss & $271.8 \pm 82.9$ & $305.6 \pm 73.2$ & \multirow{2}{*}{$<0.05$} \\
\hline & Control & $300.4 \pm 127.1$ & $280.9 \pm 125.2$ & \\
\hline \multirow{2}{*}{ Sodium (milligrams) } & Milk and Weight Loss & $3216.2 \pm 1160.7$ & $2252.8 \pm 683.6$ & \multirow{2}{*}{$<0.01$} \\
\hline & Control & $2884.2 \pm 834.1$ & $2573.9 \pm 1405.8$ & \\
\hline \multirow{2}{*}{ Potassium (milligrams) } & Milk and Weight Loss & $2417.1 \pm 766.2$ & $3183.3 \pm 667.1$ & \multirow{2}{*}{$<0.001$} \\
\hline & Control & $2581.1 \pm 900.5$ & $2560.2 \pm 1246.6$ & \\
\hline
\end{tabular}




\section{Discussion}

An important, practical approach adopted by the DGA 2010 document is the emphasis on patterns of eating rather than on individual foods or nutrients [7]. These guidelines also emphasize the need to control calories. An additional emphasis is on the consumption of nutrient dense foods.

Both the DGA 2010 and the IOM Report [8] emphasize potential health benefits from the consumption of increased vitamin D and calcium. In the DGA 2010 document, nutrients of concern included fiber, calcium, potassium and vitamin D. As a practical matter it would be hard to meet the new IOM guidelines for calcium and vitamin D or improve consumption of the shortfall nutrients identified by DGA 2010 without consuming more milk. Nonetheless, the American population is falling far short in consumption of low fat fluid milk or the equivalent.

The DGA 2010 also raised concerns about added fats and sugars. These concerns were largely related to the over consumption of these nutrients in the current American diet [7] and their potential adverse impact on both dietary quality and weight management. Other organizations such as the American Heart Association (AHA) have raised concerns about added sugars based on a potential to increase cardiovascular risk [26]. The AHA Guidelines, in particular, recommend that the average American adult male consume no more than 150 kilocalories s from added sugars and the average American female no more than 100 kilocalories per day [26].

As one justification for limiting nutritive sweeteners, the AHA cites some studies that suggest increased risk of elevated blood pressure from consumption of excessive amounts of added sugars [27] [28]. Other studies, however, do not support these findings [24] [29] [30]. It has been argued that degradation of fructose, which is a component of both HFCS and sucrose, may result in increased levels of uric acid which, in turn, result in endothelial dysfunction and high blood pressure [31]-[33]. Research in our laboratory has not demonstrated increases in uric acid, systolic, or diastolic blood pressure in response to increased consumption of sugar sweetened beverages at up to the $90^{\text {th }}$ percentile population consumption level for fructose [34].

Some epidemiologic studies have suggested that there is an increased risk of obesity and poor dietary quality amongst individuals who consume large amounts of sugar sweetened beverages [35]-[37]. However, other studies, including several from our research laboratory, have not confirmed these findings [38]. Given the complexity of human weight control, it is unlikely that one nutrient plays a major role in causing weight gain or obesity.

Some studies have suggested that added sugars may contribute to lipid abnormalities. Increased triglycerides have often been found in response to increased simple sugars in the diet [39], although this finding is often confounded by weight gain. A recent meta-analysis indicated that in the absence of weight gain, fructose containing sugars did not yield increased triglycerides [40]. Diets that substitute carbohydrates from whole grains, fruits, vegetables, and low fat or nonfat dairy products for fats such as the DASH Diet (Dietary Approaches to Stop Hypertension), do not raise triglycerides, although high density lipoprotein typically declines [41]. The higher carbohydrate diet employed in the Women's Health Initiative had no effect on either triglycerides or high density lipoprotein [42]. Some investigators have suggested that added sugars may increase abnormalities by raising low density lipoprotein (LDL) [43] [44], although research in our laboratory has yielded no change in either LDL or total cholesterol [34] [45].

The individuals in the hypocaloric milk consuming group in the current study lost an average of $11 \mathrm{lbs}$. over the 12 week period. This is consistent with the caloric deficit achieved during this study (see Table 3). In contrast, the individuals in the control group lost an average of approximately two lbs. This suggests that individuals were able to incorporate average amounts of sweetener in a hypocaloric diet without impeding weight loss. We have previously demonstrated a similar finding in a larger weight loss study [45].

Some research has suggested that consumption of added sugars may increase visceral abdominal fat [46] [47]. If this were true, it could increase risk factors for the metabolic syndrome, diabetes, and heart disease. In the current study, the individuals in the intervention group lost an average of approximately $1 / 2 \mathrm{~kg}$ of fat in the android region compared with controls. While this is consistent with the overall weight loss in the study, it suggests that, at the very least, consumption of average amounts of added sugars does not impede abdominal weight loss. Some research has also suggested that milk consumption may enhance abdominal weight loss [48] [49]. This represents a potential confounder of the current research. Thus, the abdominal weight loss in the current study should be treated with some caution.

In the current study, we explored the impact on dietary quality of consuming sweetened milk at normal population consumption levels of fructose during a supervised weight loss program. The following findings are of 
note from the current study. First, individuals who followed an overall healthy, hypocaloric diet, lost weight compared to a control group even when consuming either $10 \%$ or $20 \%$ of calories from low fat milk sweetened with HFCS or sucrose. Secondly, these individuals improved their dietary quality by significantly increasing vitamin D, calcium, magnesium and potassium through increased consumption of flavored, low fat milk. The increases in calories from the added sugars in the low fat milk were largely compensated by decreased calories from fat. Also, some relatively minor decreases occurred in alcohol consumption and percentage of calories from alcohol. In addition, overall energy significantly decreased in all weight loss groups as did sodium. Third, there was a high level of compliance to the recommended servings of sweetened milk. This underscores a key consideration that sweeteners may improve the palatability of a nutrient dense food such as flavored milk and, hence, increase the likelihood that these foods will be consumed. Fourth, there were no differences in any parameter between HFCS and sucrose at either $10 \%$ or $20 \%$ of overall calories.

The strengths of the current study include that it is the first blinded, randomized clinical trial to our knowledge to assess the impact of meeting the DGA 2010 recommendations for milk consumption during weight loss. Limitations include that no adolescents or individuals over the age of 60 were included in the study. The study was also of short duration, lasting only 24 weeks. Whether or not these findings would hold for longer study or a study with a wider age group remains an issue to be determined by future research.

We wish to emphasize that we are not advocating excessive consumption of added sugars. The hypocaloric diets employed in the current research utilized added sugar consumption levels at the $25^{\text {th }}$ and $50^{\text {th }}$ percentile of consumption in the American diet [50]. Whether these findings would hold for a diet containing higher levels of added sugar would represent an important topic for future research.

\section{Conclusion}

In summary, overweight or obese individuals in the current study were able to effectively lose weight and improve their dietary quality during weight loss while consuming $10 \%$ or $20 \%$ of their calories from flavored milk sweetened with either high fructose corn syrup or sucrose when consumed as components of a well-designed hypocaloric diet. Dietary quality was improved, particularly in the areas of shortfall nutrients, including vitamin $\mathrm{D}$, calcium and potassium. Individuals were largely able to compensate for the increased calories from the milk by decreasing the fat in their diet. These findings suggest that the level of low fat milk consumption recommended by the DGA 2010 can be achieved utilizing flavored milk and that the sugars found in this milk do not inhibit healthy weight loss when consumed in the context of a structured hypocaloric diet.

\section{Acknowledgements}

The current study was funded through an unrestricted grant from the Corn Refiners Association.

\section{Conflicts of Interest}

The only co-author who has listed any conflicts of interest is Dr. James Rippe. Dr. Rippe has received consulting fees from a variety of companies, organizations, publishers or trade associations that utilize, market, or publish information about fructose, high fructose corn syrup or sucrose and, hence, have an ongoing interest in the metabolism and health effects of these sugars.

\section{References}

[1] Fiorito, L.M., Mitchell, D.C., Smiciklas-Wright, H. and Birch, L.L. (2006) Dairy and Dairy-Related Nutrient Intake during Middle Childhood. Journal of the American Dietetic Association, 4, 534-542. http://dx.doi.org/10.1016/j.jada.2006.01.005

[2] Moore, C.E., Murphy, M.M. and Holick, M.F. (2005) Vitamin D Intakes by Children and Adults in the United States Differ among Ethnic Groups. Journal of Nutrition, 35, 2478-2485.

[3] Albertson, A.M., Tobelmann, R.C. and Marquart, L. (1997) Estimated Dietary Calcium Intake and Food Sources for Adolescent Females: 1980-92. Journal of Adolescent Health, 20, 20-26. http://dx.doi.org/10.1016/S1054-139X(96)00179-6

[4] Bowman, S.A. (2002) Beverage Choices of Young Females: Changes and Impact on Nutrient Intakes. Journal of the American Dietetic Association, 102, 1234-1239. http://dx.doi.org/10.1016/S0002-8223(02)90273-7

[5] Huth, P.J., Di Renienzo, D.B. and Miller, G.D. (2006) Major Scientific Advances with Dairy Foods in Nutrition and 
Health. Journal of Dairy Science, 4, 1207-1221. http://dx.doi.org/10.3168/jds.S0022-0302(06)72190-7

[6] Teegarden, D., Lylem, R.M., Proulx, W.R., Johnston, C.C. and Weaver, C.M. (1999) Previous Milk Consumption Is Associated with Greater Bone Density in Young Women. American Journal of Clinical Nutrition, 69, 1014-1017.

[7] Center for Nutrition Policy and Promotion (2010) Report of the Dietary Guidelines Advisory Committee on the Dietary Guidelines for Americans. US Department of Agriculture, Washington DC.

http://www.nutriwatch.org/05Guidelines/dga_advisory_2010.pdf.

[8] Institute of Medicine (2010) Dietary Reference Intakes for Calcium and Vitamin D. http://www.iom.edu/Reports/2010/Dietary-Reference-Intakes-for-Calcium-and-Vitamin-D.aspx

[9] US Department of Health and Human Services (2010) Healthy People 2010: Understanding and Improving Health. 2nd Edition, US Government Printing Office, Washington DC. http://www.healthypeople.gov/2010/?visit=1

[10] www.foodpyramid.com

[11] Cook, A. and Friday, J. (2005) Pyramid Servings Intakes in the United States 1999-2002, 1 Day. US Department of Agriculture, Agricultural Research Service, Community Nutrition Research Group, CNRG Table Set. 3. http://www.ars.usda.gov/sp2UserFiles/Place/12355000/foodlink/ts_3-0.pdf

[12] Sebastian, R.S., Goldman, J.D., Ennis, C.W. and LaComb, R.P. (2013) Fluid Milk Consumption in the United States. What We Eat in America, NHANES 2005-2006. http://www.ars.usda.gov/ba/bhnrc/fsrg

[13] Flegal, K.M., Carroll, M.D., Kit, B.K. and Ogden, C.L. (2012) Prevalence of Obesity and Trends in the Distribution of Body Mass Index. The Journal of the American Medical Association, 307, 491-497. http://dx.doi.org/10.1001/jama.2012.39

[14] National Center for Health Examination Surveys II and III (2013) National Health and Nutrition Examination Surveys I, II, III and 1999-2004. NCHs, CDC, Atlanta. http://www.cdc.gov/nchs/nhanes/nhanes_questionnaires.htm

[15] US Department of Health and Human Services, Public Health Service (2013) The Surgeon General's Call to Action to Prevent and Decrease Overweight and Obesity 2001. http://www.surgeongeneral.gov/library/calls/obesity/index.html

[16] Sacks, F.M., Bray, G.A., Carey, V.J., Smith, S.R., Ryan, D.H., Anton, S.D., McManus, K., Champagne, C.M., Bishop, L.M., Laranjo, N., Leboff, M.S., Rood, J.C., de Jonge, L., Greenway, F.L., Loria, C.M., Obarzanek, E. and Williamson, D.A. (2009) Comparison of Weight-Loss Diets and Different Compositions of Fat, Protein, and Carbohydrates. New England Journal of Medicine, 360, 859-873. http://dx.doi.org/10.1056/NEJMoa0804748

[17] Luscombe-Marsh, N.D., Noakes, M., Wittert, G.A., Keough, J.B., Foster, P. and Clifton, P.M. (2005) Carbohydrate Restricted Diets High in Either Monounsaturated Fat or Protein Are Equally Effective in Promoting Fat Loss and Improving Blood Lipids. American Journal of Clinical Nutrition, 81, 762-772.

[18] Keogh, J.B., Luscombe-Marsh, N.D., Noakes, M., Wittert, G.A. and Clifton, P.M. (2007) Long Term Weight Management and Cardiovascular Risk Factors are Not Different Following Weight Loss on Carbohydrate-Restricted Diets High in Either Monounsaturated Fat or Protein in Obese Hyperinsulinemic Men and Women. British Journal of Nutrition, 97, 405-410.

[19] Ebbeling, C.B., Swain, J.F., Feldman, H.A., Wong, W.W., Hachey, D.L., Garcia-Lago, E. and Ludwig, D.S. (2012) Effects of Dietary Composition on Energy Expenditure during Weight-Loss Maintenance. The Journal of the American Medical Association, 307, 2627-2634. http://dx.doi.org/10.1001/jama.2012.6607

[20] Foster, G.D., Wyatt, H.R., Hill, J.O., McGuckin, B.G., Brill, C., Mohammed, S., Szapary, P.O., Rader, D.J., Edman, J.S. and Klein, S. (2003) Randomized Trial of a Low-Carbohydrate Diet for Obesity. New England Journal of Medicine, 348, 2082-2090. http://dx.doi.org/10.1056/NEJMoa022207

[21] Stokes, D.M. (2012) Council Has Power to Ensure Kids Get Much-Needed Milk. http://www.miltonstakes.com/pdfs/press_clip_11.pdf

[22] Milk PEP. Washington DC. http://www.milkpep.org

[23] (2002) Promar International. School Milk Pilot Test: Estimating the Effects of National Implementation. A Report Prepared for the National Dairy Council and the American School Food Service Association. Promar International, Alexandria, VA. http://www.ibrarian.net/navon/page.jsp?paperid=1060631\&searchTerm=109+cd

[24] Rippe, J. and Angelopoulos, T. (2013) Sucrose, High Fructose Corn Syrup and Fructose, and Their Potential Health Effects: What Do We Really Know? Advances in Nutrition, 4, 236-245. http://dx.doi.org/10.3945/an.112.002824

[25] Mifflin, M.D., St Jeor, S.T., Hill, L.A., Scott, B.J., Daugherty, S.A. and Koh, Y.O. (1990) A New Predictive Equation for Resting Energy Expenditure in Healthy Individuals. American Journal of Clinical Nutrition, 51, 241-247.

[26] Johnson, R.K., Appel, L.J., Brands, M., Howard, B.V., Lefevre, M., Lustig, R.H., Sacks, F., Steffen, L.M., WylieRosett, F., on Behalf of the American Heart Association Nutrition Committee of the Council on Nutrition, Physical Activity and Metabolism and the Council on Epidemiology and Prevention (2009) Dietary Sugars Intake and Cardiovascular Health: A Scientific Statement from the American Heart Association. Circulation, 120, 1011-1020. 
[27] Nguyen, S., Choi, H.K., Lustig, R.H. and Hsu, C.Y. (2009) Sugar-Sweetened Beverages, Serum Uric Acid, and Blood Pressure in Adolescents. Journal of Pediatrics, 154, 807-813. http://dx.doi.org/10.1016/j.jpeds.2009.01.015

[28] Bremer, A.A., Auinger, P. and Byrd, R.S. (2009) Relationship between Insulin Resistance-Associated Metabolic Parameters and Anthropometric Measurements with Sugar-Sweetened Beverage Intake and Physical Activity Levels in US Adolescents: Findings from the 1999-2004 National Health and Nutrition Examination Survey. Archives of Pediatrics and Adolescent Medicine, 163, 328-335.

[29] Van der Schaaf, M.R., Koomans, H.A. and Joles, J.A. (1999) Dietary Sucrose Does Not Increase Twenty-Four-Hour Ambulatory Blood Pressure in Patients with Either Essential Hypertension or Polycystic Kidney Disease. Journal of Hypertension, 17, 453-454. http://dx.doi.org/10.1097/00004872-199917030-00020

[30] Ha, V., Sievenpiper, J.L., de Souza, R.J., Chiavaroli, L., Wang, D.D., Cozma, A.I., Mirrahimi, A., Yu, M.E., Carleton, A.J., Dibuono, M., Jenkins, A.L., Leiter, L.A., Wolever, T.M.S., Beyene, J., Kendall, C.W.C. and Jenkins, D.J.A. (2012) Effect of Fructose on Blood Pressure: A Systematic Review and Meta-Analysis of Controlled Feeding Trials. Hypertension, 59, 787-795. http://dx.doi.org/10.1161/HYPERTENSIONAHA.111.182311

[31] Johnson, R.J., Segal, M.S., Sautin, Y., Nakagawa, T., Feig, D.I., Kung, D.H., Gersch, M.S., Benner, S. and SanchezLozada, L.G. (2007) Potential Role of Sugar (Fructose) in The Epidemic of Hypertension, Obesity and the Metabolic Syndrome, Diabetes, Kidney Disease, and Cardiovascular Disease. American Journal of Clinical Nutrition, 86, 899906.

[32] Kang, D.H., Park, S.K., Lee, I.K. and Johnson, R.J. (2005) Uric Acid-Induced C-Reactive Protein Expression: Implication on Cell Proliferation and Nitric Oxide Production of Human Vascular Cells. Journal of the American Society of Nephrology, 16, 3553-3562. http://dx.doi.org/10.1681/ASN.2005050572

[33] Khosla, U.M., Zharikov, S., Finch, J.L., Nakagawa, T., Roncal, C., Mu, W., Krotova, K., Block, E.R., Prabhakar, S. and Johnson, R.J. (2005) Hyperuricemia Induces Endothelial Dysfunction. Kidney International, 67, 1739-1742.

[34] Lowndes, J., Sinnett, S., Yu, Z. and Rippe, J. (2012) Effects of Fructose Containing Sugars on Lipids, Blood Pressure and Uric Acid When Consumed at up to 90th Percentile Population Consumption Levels. Circulation, 126, Article ID: A13066.

[35] Malik, V.S., Schulze, M.B. and Hu, F.B. (2006) Intake of Sugar-Sweetened Beverages and Weight Gain: A Systematic Review. American Journal of Clinical Nutrition, 84, 274-288.

[36] Olsen, N.J. and Heitmann, B.L. (2009) Intake of Calorically Sweetened Beverages and Obesity. Obesity Reviews, 10, 68-75.

[37] Bray, G. (2010) Fructose: Pure, White and Deadly? Fructose by Any Other Name Is a Health Hazard. Journal of Diabetes Science and Technology, 4, 1003-1007. http://dx.doi.org/10.1177/193229681000400432

[38] Forshee, R.A., Anderson, P.A. and Storey, M.L. (2008) Sugar-Sweetened Beverages and Body Mass Index in Children and Adolescents: A Meta-Analysis. American Journal of Clinical Nutrition, 87, 1662-1671.

[39] Hellerstein, M.K. (2002) Carbohydrate-Induced Hypertriglyceridemia: Modifying Factors and Implications for Cardiovascular Risk. Current Opinion in Lipidology, 13, 33-40. http://dx.doi.org/10.1097/00041433-200202000-00006

[40] Sievenpiper, J.L., de Souza, R.J., Mirrahimi, A., Yu, M.E., Carleton, A.J., Beyene, J., Chiavaroli, L., Di Buono, M., Jenkins, A.L., Leiter, L.A., Wolever, T.M.S., Kendall, C.W.C. and Jenkins, D.J.A. (2012) Effect of Fructose on Body Weight in Controlled Feeding Trials: A Systematic Review and Meta-Analysis. Annals of Internal Medicine, 156, 291304. http://dx.doi.org/10.7326/0003-4819-156-4-201202210-00007

[41] Obarzanek, E., Sacks, F.M., Vollmer, W.M., Bray, G.A., Miller III, E.R., Lin, P.H., Karanja, N.M., Most-Windhauser, M.M., Moore, T.J., Swain, J.F., Bales, C.W., Proschan, M.A. and DASH Research Group (2001) Effects on Blood Lipids of a Blood Pressure-Lowering Diet: The Dietary Approaches to Stop Hypertension (DASH) Trial. American Journal of Clinical Nutrition, 74, 80-89.

[42] Howard, B.V., Van Horn, L., Hsia, J., Manson, J.E., Stefanick, M.L., Wassertheil-Smoller, S., Kuller, L.H., LaCroix, A.Z., Langer, R.D., Lasser, N.L., et al. (2006) Low-Fat Dietary Pattern and Risk of Cardiovascular Disease: The Women's Health Initiative Randomized Controlled Dietary Modification Trial. The Journal of the American Medical Association, 295, 655-666.

[43] Stanhope, K.L., Bremer, A.A., Medici, V., Nakajima, K., Ito, Y., Nakana, T., Chen, G., Fong, T.H., Lee, V., Menorca, R.I., Keim, N.L. and Havel, P.J. (2011) Consumption of Fructose and High Fructose Corn Syrup Increase Postprandial Triglycerides, LDL-Cholesterol, and Apolipoprotein-B in Young Men and Women. Journal of Clinical Endocrinology and Metabolism, 17, 2011-1251. http://dx.doi.org/10.1210/jc.2011-1251

[44] Marckmann, P. (2000) Dietary Treatment of Thrombogenic Disorders Related to the Metabolic Syndrome. British Journal of Nutrition, 83, S121-S126. http://dx.doi.org/10.1017/S0007114500001057

[45] Lowndes, J., Kawiecki, D., Pardo, S., Nguyen, V., Melanson, K., Yu, Z.P. and Rippe, J.M. (2012) The Effects of Four Hypocaloric Diets Containing Different Levels of Sucrose or High Fructose Corn Syrup on Weight Loss and Related 
Parameters. Nutrition Journal, 11, 55. http://dx.doi.org/10.1186/1475-2891-11-55

[46] Maersk, M., Belza, A., Stodkilde-Jorgensen, H., Ringgaard, S., Chabanova, E., Thomsen, H., Pedersen, S.B., Astrup, A. and Richelsen, B. (2011) Sucrose-Sweetened Beverages Increase Fat Storage in the Liver, Muscle, and Visceral Fat Depot: A 6-Mo Randomized Intervention Study. American Journal of Clinical Nutrition, 95, 283-289.

http://dx.doi.org/10.3945/ajcn.111.022533

[47] Stanhope, K. and Havel, P. (2008) Fructose Consumption: Potential Mechanisms for Its Effects to Increase Visceral Adiposity and Induce Dyslipidemia and Insulin Resistance. Current Opinion in Lipidology, 19, 16-24. http://dx.doi.org/10.1097/MOL.0b013e3282f2b24a

[48] Zemel, M.B., Thompson, W., Milstead, A., Morris, K. and Campbell, P. (2004) Calcium and Dairy Acceleration of Weight and Fat Loss during Energy Restriction in Obese Adults. Obesity Research, 12, 582-590.

http://dx.doi.org/10.1038/oby.2004.67

[49] Zemel, M.B., Richards, J., Mathis, S., Milstead, A., Gebhardt, L. and Silva, E. (2005) Dairy Augmentation of Total and Central Fat Loss in Obese Subjects. International Journal of Obesity, 29, 391-397. http://dx.doi.org/10.1038/sj.ijo.0802880

[50] Marriott, B.P., Olsho, L., Hadden, L. and Connor, P. (2010) Intake of Added Sugars and Selected Nutrients in the United States, National Health and Nutrition Examination Survey (NHANES) 2003-2006. Critical Reviews in Food Science and Nutrition, 50, 228-258. http://dx.doi.org/10.1080/10408391003626223 